\title{
Role of endoscopy in gastroesophageal reflux disease
}

\author{
Tarun Rai, Prashanth Vennalaganti, Prateek Sharma
}

Division of Gastroenterology and Hepatology, Veterans Affairs Medical Center and University of Kansas, School of Medicine, Kansas City, USA

Abstract $\begin{aligned} & \text { Gastroesophageal reflux disease is a condition due to reflux of stomach content in the esophagus } \\ & \text { causing trouble symptoms or complications or both. GERD is a clinical diagnosis and typically } \\ & \text { presents with a heartburn and/or regurgitation and a positive response to antacid secretory } \\ & \text { medications. GERD is the leading outpatient diagnosis among all gastrointestinal disorders } \\ & \text { in the United States. Approximately } 40 \% \text { of population report occasional symptoms of GERD } \\ & \text { whereas } 10-20 \% \text { of patients will have symptoms at least once in a week. Recent guidelines from } \\ & \text { gastrointestinal societies such as American College of Gastroenterology, American Society for } \\ & \text { Gastrointestinal Endoscopy and American College of Physicians have laid out specific indications } \\ & \text { regarding role of esophagogastroduodenoscopy in GERD. Despite these recommendations, } \\ & \text { studies have revealed that one-fifth to two-fifth EGDs may not be clinically indicated, especially } \\ & \text { where open access endoscopy referral system is used. Traditionally, GERD has been thought } \\ & \text { to be a disease of the western world. Prevalence rates had been estimated to be lower in Asia } \\ & \text { when compared to that of the Western Countries. Few recent epidemiological studies in India } \\ & \text { showed the prevalence of reflux disease in India to be between } 8-24 \% \text {, which is comparable } \\ & \text { to the western world. The use of EGDs becomes more critical for developing countries such } \\ & \text { as India where prevalence of GERD and BE is comparable to the western countries but have } \\ & \text { limited resources. In addition to direct cost for an EGD, it burdens economy with indirect } \\ & \text { costs such as time off from the work, transportation and any procedural complications. Risk } \\ & \text { stratifying patients with GERD may therefore prevent unnecessary procedures, harms and costs. } \\ & \text { The aim of this paper is to review the existing evidence on the role of endoscopy in GERD. }\end{aligned}$
$\begin{aligned} & \text { Barrett's esophagus, endoscopy, gastroesophageal reflux disease } \\ & \text { Key words }\end{aligned}$

\section{Introduction}

The Montreal Consensus Conference defines gastroesophageal reflux disease (GERD) as a condition due to reflux of stomach content in the esophagus causing trouble symptoms or complications or both..$^{[1]}$ Endoscopic or histologic changes are not necessary to make the diagnosis. GERD is a clinical

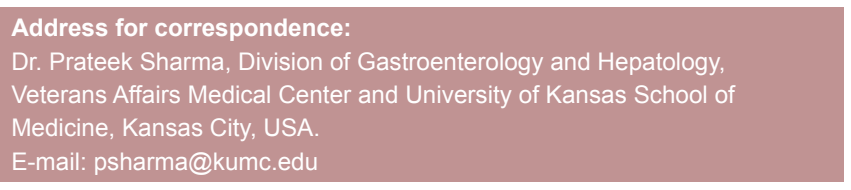

\begin{tabular}{|l|c|}
\hline \multicolumn{2}{|c|}{ Access this article online } \\
\hline \multirow{2}{*}{$\begin{array}{l}\text { Website: } \\
\text { www.jdeonline.in }\end{array}$} & Quick Response Code \\
\hline DOI: & \\
10.4103/0976-5042.165686 & \\
\hline
\end{tabular}

diagnosis and typically presents with heartburn and/or regurgitation and a positive response to antacid secretory medications.

GERD is the leading outpatient diagnosis among all gastrointestinal (GI) disorders in the United States. Approximately $40 \%$ of the population report occasional symptoms of GERD whereas $10-20 \%$ of patients will have symptoms at least once in a week. ${ }^{[2-4]}$ Proton-pump inhibitors (PPIs) are the main stay of GERD therapy. At least, a PPI has been in the list of top-five bestselling medications, both by volume as well as sales in 2007-2012.

This is an open access article distributed under the terms of the Creative Commons Attribution-NonCommercial-ShareAlike 3.0 License, which allows others to remix, tweak, and build upon the work non-commercially, as long as the author is credited and the new creations are licensed under the identical terms.

For reprints contact: reprints@medknow.com

How to cite this article: Rai T, Vennalaganti P, Sharma P. Role of endoscopy in gastroesophageal reflux disease. J Dig Endosc 2015;6:89-95. 
Recent guidelines from GI societies such as American College of Gastroenterology (ACG), American Society for GI Endoscopy (ASGE), and American College of Physicians (ACP) have laid out specific indications regarding role of esophagogastroduodenoscopy (EGD) in GERD. Despite these recommendations, studies have revealed that one-fifth to two-fifth EGDs may not be clinically indicated, especially where open access endoscopy referral system is used. ${ }^{[5]}$ The number of EGDs performed per year in the USA for Medicare patients has increased by $40 \%$ in recent years whereas the enrollment has increased only by $13 \%$ (www. cms.gov/NonIdentifiableDataFiles). The aim of this paper is to review the existing evidence on the role of endoscopy in GERD.

\section{Burden of Gastroesophageal Reflux Disease in India and Asia}

Traditionally, GERD has been thought to be a disease of the Western world. Prevalence rates had been estimated to be lower in Asia when compared to that of the Western countries. ${ }^{[6]} \mathrm{Few}$ recent epidemiological studies in India showed the prevalence of reflux disease in India to be between $8 \%$ and $24 \%,{ }^{[7,8]}$ which is comparable to the Western world. Epidemiological studies have reported variable prevalence of Barrett's esophagus (BE) in Asian population, between $1 \%$ and $42 \%,{ }^{[9,10]}$ with higher prevalence of short segment nondysplastic BE (NDBE) as compared to long segment NDBE. In India, the prevalence of $\mathrm{BE}$ has reported to be between $2.4 \%$ and $23.6 \%{ }^{[11,12]}$ The heterogeneity in the findings could be secondary to methods used for diagnosis as well as the selected population being evaluated. In the retrospective study by Punia et al. ${ }^{[11]}$ with reported $23.6 \%$ prevalence of $\mathrm{BE}$, half of the patients with gastric metaplasia were classified as having BE. So the true prevalence of $\mathrm{BE}$ was approximately $10 \%$ in GERD patients with typical symptoms. However, it is unclear if this represents a true increase in the prevalence of GERD or is a result of better understanding of the disease symptoms, increased awareness of acid reflux, or the recent high quality epidemiological studies. Nonetheless, the impact of the adaptation of "western diet and lifestyle" increasing obesity, reducing Helicobacter pylori frequency, etc., on the increase in the prevalence of GERD cannot be ruled out. In India, the future "Diabetes Capital of the World," the prevalence of GERD and BE may increase further.

\section{Burden of Gastroesophageal Reflux Disease and Utilization of Endoscopy in the USA}

Among patient reported symptoms, abdominal pain was the leading cause of outpatient clinic appointments with approximately 16 million visits in 2009. ${ }^{[13]}$ Heartburn and indigestion were the sixth leading symptom that led to 2 million
GI clinic visits. Among all GI disorders, GERD was the number one physician diagnosis in outpatient clinics and the patients discharged from hospitals. ${ }^{[13]}$ There were half a million doctor visits for $\mathrm{BE}$.

Of 6.9 million EGDs performed in 2009, the presence of alarm symptoms such as anemia, weight loss, bleeding, or vomiting was the most common indication (28.4\%). ${ }^{[13]}$ GERD alone was an indication for EGD in $19.2 \%$ of cases whereas reflux or dysphagia was indicated in 23.9 and $20.3 \%$ endoscopies, respectively. An estimated direct cost of all EGDs performed was $\$ 12.3$ billion. The average direct cost per upper endoscopy was $\$ 1,775 \cdot{ }^{[13]}$ Indirect costs include decreased quality of life work, decreased productivity, and time off from work both for the patient and the attendant. Patients with abdominal pain, GERD, and bloating scored similar to those with depression and heart failure in the National Health and Wellness Survey, 2000 which assessed quality of life in terms of physical, mental, and activity impairment. ${ }^{[13]}$

\section{Role of Endoscopy in the Diagnosis of Gastroesophageal Reflux Disease}

The typical symptoms of GERD are regurgitation and heartburn. Atypical symptoms include cough, chest pain, abdominal pain, and extraesophageal symptoms are hoarseness of voice, cough, and asthma. On EGD, approximately $40-50 \%$ of patients with prolonged reflux will have findings of esophagitis. ${ }^{[1,14,15]}$ The presence of esophagitis is $90-95 \%$ specific but not sensitive for the diagnosis of GERD. ${ }^{[14,16,17]}$ The response to PPI has also been advocated for GERD diagnosis. The problem with this definition is that the response rate to PPI is variable. For patients with severe degree of inflammation, the response rate is as high as $90 \%$ whereas for patients with Los Angeles (LA) Grade A or LA Grade B esophagitis, the response rate could be as low as $40-50 \% \cdot{ }^{[18,19]}$ Patients with normal esophageal findings on EGD are often referred to as having nonerosive reflux disease.

The most common classification currently used to grade the severity of esophagitis is the LA classification [Table 1 and Figure 1]. ${ }^{[20]}$ The LA classification is reliable and has shown good intra-observer and inter-observer agreement among endoscopists. It also correlates well with the amount of acid exposure based on $24 \mathrm{~h} \mathrm{pH}$-testing. A limitation of these scoring systems is that the endoscopic findings fail to predict the symptom severity.

\section{Histological Findings in Gastroesophageal Reflux Disease}

Initial reports in 1970s suggested that basal cell hyperplasia and elongation of papilla correlated well with the presence of GERD. ${ }^{[21,22]}$ However recent studies, including a large prospective GERD trial (The ProGERD Study), ${ }^{[23]}$ failed to 
find any significant difference in basal cell hyperplasia and elongation of papilla in patients with GERD symptoms and with or without erosive changes. In this study, biopsies were obtained $2 \mathrm{~cm}$ above the gastroesophageal junction (Z-line). The presence of intraepithelial inflammatory cells had high specificity but low sensitivity as it could be present in normal appearing mucosa in subjects without reflux symptoms.

Dilated intercellular space, seen on transmission electron microscopy has been proposed as one of the diagnostic characteristics of GERD. Intercellular spaces were dilated twice as much in patients with reflux symptoms compared

\begin{tabular}{l}
\hline $\begin{array}{l}\text { Table 1: The modified LA classification system for the } \\
\text { endoscopic assessment of grade of esophagitis }\end{array}$ \\
\begin{tabular}{ll} 
Grade & Description \\
\hline A & $\begin{array}{l}\text { One (or more) mucosal breaks no longer than } 5 \mathrm{~mm} \text {, none } \\
\text { of which extends between the tops of the mucosal folds }\end{array}$ \\
B $\quad \begin{array}{l}\text { One (or more) mucosal breaks more than } 5 \mathrm{~mm} \text { long, none } \\
\text { of which extends between the tops of two mucosal folds }\end{array}$ \\
C $\quad \begin{array}{l}\text { One (or more) mucosal breaks that extend between the } \\
\text { tops of two or more mucosal folds, but which involve }<75 \% \\
\text { of the esophageal circumference }\end{array}$ \\
One (or more) mucosal breaks which involve at least $75 \%$ \\
of the esophageal circumference
\end{tabular} \\
\hline
\end{tabular}
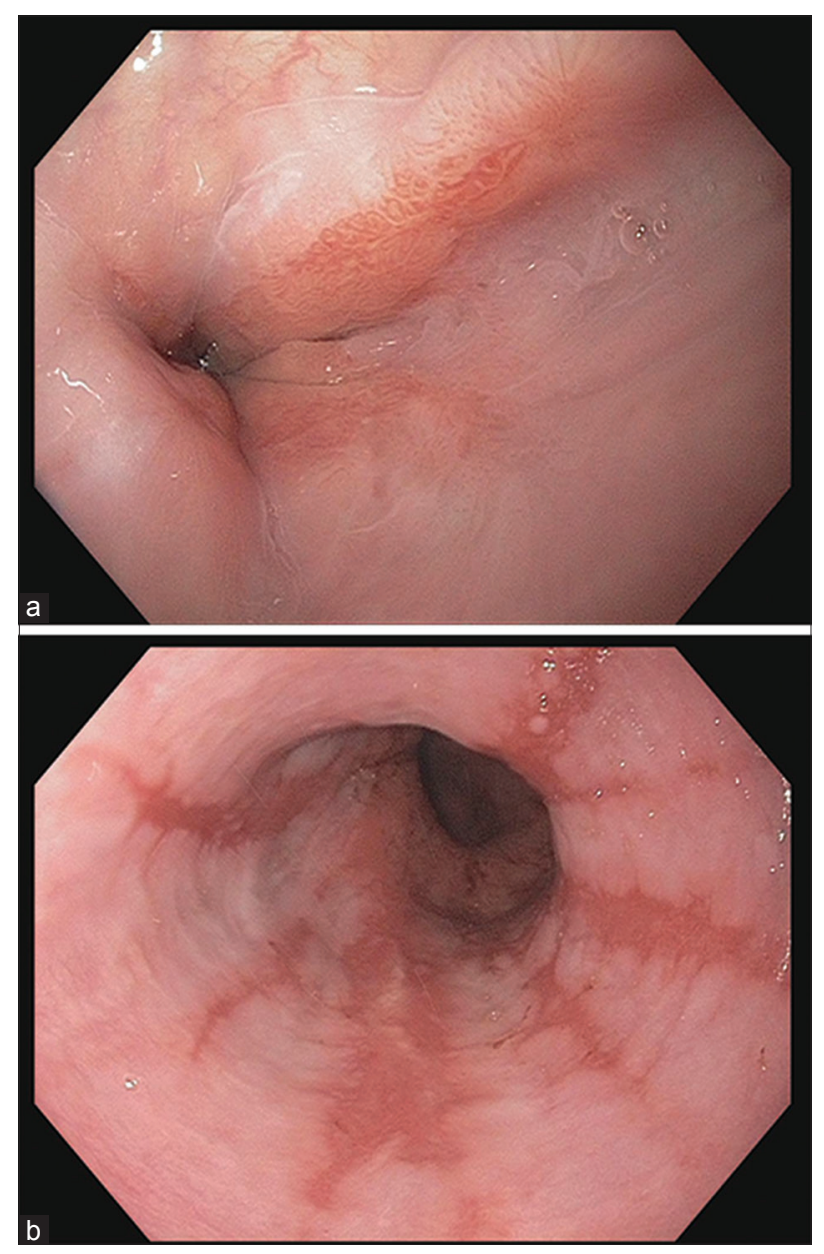

Figure 1: (a) Grade B esophagitis; (b) Grade D esophagitis to asymptomatic controls whereas no difference was noted in the symptomatic GERD patients, with and without erosive changes on EGD. ${ }^{[24,25]}$ The findings are not validated and transmission elevation microscopy is not widely available in general practice.

\section{Differential Diagnosis of Esophagitis}

In immunocompromised individuals, viral or candida infection can cause esophagitis. Herpes simplex virus (HSV) and cytomegalovirus (CMV) are the most common viral infections. HSV usually affects the distal esophagus and causes small ulcers with normal-appearing intervening mucosa. The ulcers are well circumscribed and have a "volcano-like" appearance. Biopsies should be taken from the edge of an ulcer where viral cytopathic effects are most likely to be present. Multinucleated giant cells, with ground-glass nuclei, and eosinophilic inclusions (Cowdry Type A inclusion bodies) are often seen in histology. On the other hand, CMV ulcers are more linear, longitudinal, or deeper with diffuse esophageal involvement. Large cells containing eosinophilic intranuclear and basophilic intracytoplasmic inclusions, known as cytomegalic cells are often noted in the biopsy. Candida esophagitis causes white mucosal plaque such as exudative lesions and biopsy show yeasts and pseudohyphae.

\section{Complications of Long Standing Gastroesophageal Reflux Disease}

\section{Endoscopy in Barrett's esophagus}

$\mathrm{BE}$ is a well-known complication of GERD [Figure 2]. The prevalence of $\mathrm{BE}$ is approximately $5 \%$ in patients without and $8 \%$ with a history of heartburn. Older age, male gender, Caucasian race, and higher body mass index $(\mathrm{BMI})^{[26]}$ are risk factors for $\mathrm{BE}$. $\mathrm{BE}$ is the only known precursor lesion of esophageal adenocarcinoma (EAC). Approximately, 90\% of $\mathrm{BE}$ is nondysplastic. The rate of progression of $\mathrm{NDBE}$ and

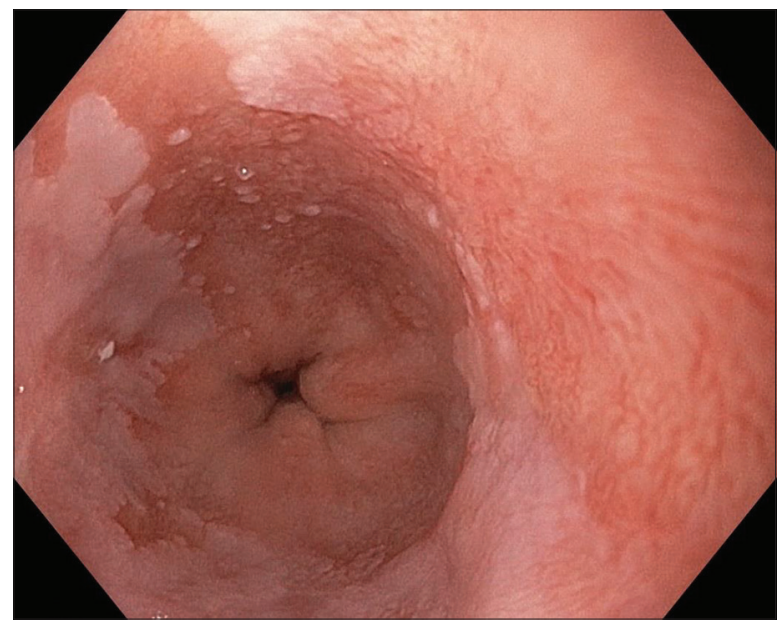

Figure 2: Endoscopic appearance of Barrett's esophagus 
low-grade dysplasia (LGD) to EAC is very low; approximately $0.3-0.4 \%$ and $0.5-1 \%$ per patient year, respectively. ${ }^{[27]}$ Figure 2 shows nondysplastic and EAC.

Given the high prevalence of GERD, the presence of $\mathrm{BE}$ without GERD symptoms and low rate of progression of NDBE to EAC, the use of EGD as a population-based screening tool is neither cost effective nor feasible. A cost utility analysis showed that screening of men above the age of 50 with long standing symptoms of GERD to detect adenocarcinoma associated with $\mathrm{BE}$ is probably cost-effective. However, even 5-year subsequent surveillance intervals for NDBE patients might exceed the current threshold of cost-effectiveness ratio $<\$ 50,000$ per Quality Life Year saved. ${ }^{[28]}$

Given above factors, most GI societies ${ }^{[29-31]}$ and $A C P^{[32]}$ recommend, EGD for BE only in men older than 50 years, with chronic GERD symptoms more than 5 years, with presence of additional risk factors such as nocturnal reflux symptoms, hiatal hernia, elevated BMI, tobacco use, and abdominal obesity. The role of EGD as once in a lifetime screening for $\mathrm{BE}$ is controversial. American Gastroenterological Association (AGA) recommends against screening the general population with GERD for BE. ${ }^{[29]}$ If no $\mathrm{BE}$ is noted on index EGD when reflux symptoms for more than 5 years, ASGE recommends against further EGD unless there is a development of new high risk symptoms such as anemia, weight loss, or dysphagia. ${ }^{[30]}$ The role of EGD in the GERD patients is summarized in Table 2.

\section{Endoscopy in dysplastic Barrett's esophagus}

$\mathrm{BE}$ with any grade of dysplasia - LGD or high-grade dysplasia (HGD), should be confirmed by two independent expert pathologists. Once the diagnosis is confirmed, AGA recommends surveillance EGD for LGD every 6 months to 1 year. Currently, ACG and ASGE do not advocate treating patients with LGD except in a select group of people. In patients with high-grade dysplasia (HGD) or EAC, AGA recommends endoscopic eradication or ablation treatment over surgery. ${ }^{[29]}$ In the absence of eradication therapy, surveillance EGD should be done every 3 months. Patients undergoing endoscopic treatment, should have an endoscopic mucosal resection (EMR) followed by an ablative technique in the presence of a visible lesion. ${ }^{[33]}$ EMR is both diagnostic and therapeutic. It allows pathologists to provide accurate diagnosis and disease staging. Endoscopic ablation alone is performed in the absence of a visible lesion or nodule. The role of EGD in surveillance of $\mathrm{BE}$ is summarized in Table 3.

Surveillance interval after endoscopic treatment is not clear at this time. Societies recommend surveillance every 3-6 months in the $1^{\text {st }}$ year followed by yearly EGDs in the absence of dysplasia. Common complications of the EMR are bleeding (1-8\%), perforation, and stricture (1-24\%) which may need dilation in symptomatic patients. Multiple sessions of EMR alone have shown to cause more stricture as compared to EMR followed by ablation. ${ }^{[34]}$ Among the ablative techniques, radiofrequency ablation (RFA) is preferred. RFA uses ultra-short pulse radiofrequency energy that ablates the dysplastic mucosa to a uniform depth of $0.5-1 \mathrm{~mm}$, while preserving the submucosa - results from the large multi-center trial showed high efficacy rates of eradication of dysplasia (90\%) and intestinal metaplasia (IM) (80\%). A multi-center study by Gupta et al. observed that of patients with $\mathrm{BE}$ treated by RFA, 56\% were in complete remission after 24 months. ${ }^{[35]}$ However, $33 \%$ of these patients had disease recurrence within the next 2 years. Though most recurrences were nondysplastic and endoscopically manageable, authors recommended continued surveillance after RFA. Long-term data on safety and efficacy of carbon dioxide cryotherapy for treatment of neoplastic BE by Canto et al. showed that at 1 year, the overall complete response rates were $77 \%$ for cancer, $89 \%$ for dysplasia, and 94\% for HGD. Thus, long-term studies on safety and efficacy of ablation for $\mathrm{BE}$ is promising.

\footnotetext{
Table 2: Role of EGD in GERD

Men and women with alarm symptoms-Dysphagia, bleeding, anemia, weight loss, and recurrent vomiting

Persistence of typical GERD symptoms after therapeutic trial of twice daily PPI for 4-8 weeks

Surveillance for severe esophagitis (LA grade C/D) after a 2 months trial of twice daily PPI to R/O BE

Evaluation for suspected extraesophageal manifestations of GERD

Findings of mass/stricture on imaging studies

Symptom control for dysphagia in patients with benign or malignant stricture

Screening for BE in men with reflux symptoms for more than

5 years, age above 50 and presence of other risk factors such as (nocturnal symptoms, hiatal hernia, abdominal obesity, high body mass index, and tobacco use)

Evaluation of patients undergoing surgical anti-reflux procedures

Evaluation of patients with recurrent reflux symptoms and alarm symptoms such as abdominal pain, vomiting, anemia, or weight loss after anti-reflux surgery

EGD=Esophagogastroduodenoscopy, GERD=Gastroesophageal reflux disease PPI=Proton-pump inhibitors, BE=Barrett's Esophagus, LA=Los Angeles
}
Table 3: Role of EGD in surveillance of BE
NDBE
EGD should be performed no more frequently than every 3-5 years, with white-light endoscopy and targeted plus 4-quadrant biopsies at every $2 \mathrm{~cm}$ of suspected $B E^{\mathrm{a}, \mathrm{b}}$
Repeat EGD at 1 year and then every 3 years $^{a}$ LGD
Repeat endoscopy within 6 months to confirm the diagnosis, and then, annual surveillance endoscopy using a standard biopsy protocol ${ }^{b, c}$ HGD
Endoscopic treatment (preferred) or surgery can consider surveillance every 3 months ${ }^{c}$
${ }^{\mathrm{a} A C G}$, ${ }^{\mathrm{b}} \mathrm{ASGE},{ }^{\mathrm{C}} \mathrm{AGA}$. EGD=Esophagogastroduodenoscopy, BE=Barrett's Esophagus, LGD=Low-grade dysplasia, HGD=High-grade dysplasia, NDBE=Nondysplastic Barrett's esophagus, ACG=American College of Gastroenterology, ASGE=American Society for Gastrointestinal Endoscopy, AGA=American Gastroenterological Association




\section{Advanced imaging techniques in Barrett's esophagus}

White light endoscopy with random biopsies is the standard for detection of IM and neoplasia in patients with BE. In a meta-analysis by Qumseya et al., it was noted that advanced imaging techniques increased the diagnostic yield for detection of dysplasia or cancer by $34 \%$. ${ }^{[36]}$ Virtual chromoendoscopy (narrow band imaging [NBI]) or chromoendoscopy were the advanced imaging technique studied. There was no difference in the diagnostic yield for dysplasia between NBI or chromoendoscopy. ${ }^{[36]}$ NBI highlights surface patterns that correlate with IM and neoplasia in BE. In another study, Sharma et al. noted that NBI targeted biopsies can have the same IM detection rate as a high-definition white light examination with the Seattle protocol while requiring fewer biopsies. ${ }^{[3]}$ In addition, NBI targeted biopsies detected more areas with dysplasia. Regular appearing NBI surface patterns did not harbor HGD/cancer, suggesting that biopsies could be avoided in these areas.

\section{Endoscopy in strictures}

Long standing reflux disease can cause esophageal strictures. Figure 3 shows a typical peptic stricture. Dysphagia is the chief symptom. The role of endoscopy is to differentiate malignant and benign strictures. The incidence of benign strictures has decreased due to the widespread use of PPIs. Empiric dilation in the absence of symptoms is not recommended. ${ }^{[38]}$ In benign strictures, dilation is attempted as need basis for symptom control. Malignant strictures need self-expandable metallic or frequent dilation as compared to benign strictures for symptom control.

In common practice, nonwire guided mercury or tungsten filled bougies (Maloney or Hurst), wire guided polyvinyl dilators (Savary-Gillard or American), and through-the-scope balloon dilators are used. During dilation, the "rule of three" is followed. No greater than three consecutive dilation in increment of $1 \mathrm{~mm}$ should be used in a single session. The exception to this rule is for Schatzki ring, where the largest

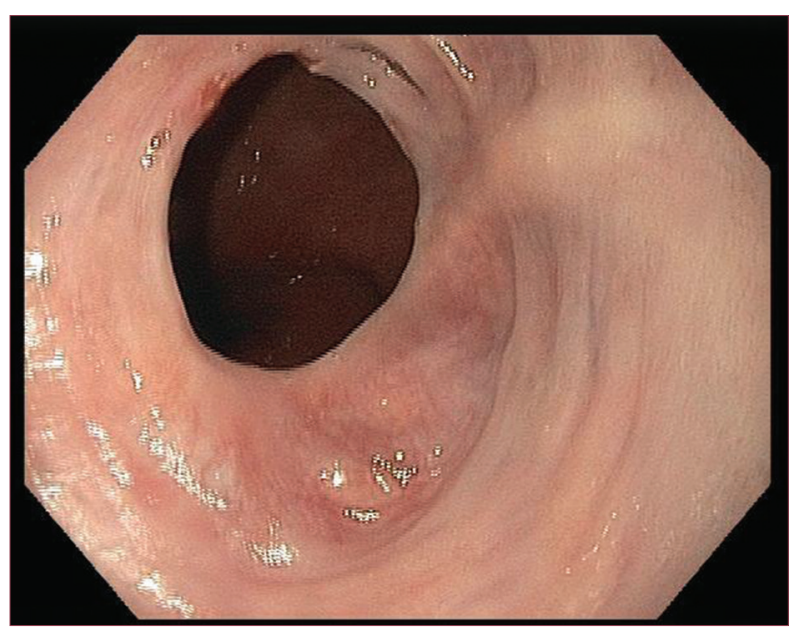

Figure 3: Benign peptic stricture diameter dilators, usually $16-20 \mathrm{~mm}$ is used with intent of disrupting the stricture. ${ }^{[38]}$ Sometimes biopsy/incision of the Schatzki ring is helpful in breaking the ring.

\section{Endoscopy for esophageal adenocarcinoma}

Esophageal neoplasia is usually classified according to the internationally accepted Vienna Classification. ${ }^{[39]}$ The Vienna Classification is based upon the histopathological evaluation of endoscopically acquired biopsies [Table 4]. Endoscopy eradication therapies are considered adequate for T1a cancers (involving mucosal layer) as the risk of lymph node metastasis is $<1-3 \% \cdot{ }^{[40]}$ Few centers consider endoscopic resection for superficial submucosal layer (T1sm1 cancers) provided the tumor is not poorly differentiated or show lymphovascular invasion. The chances of lymph node metastasis are more than $20 \%$ in patients with any cancer beyond T1sm1 ${ }^{[41]}$ EMR has shown good results for early EAC in conjunction with RFA. Haidry et al. showed that HGD was cleared from $86 \%$ of patients, all dysplasia from $81 \%$, and BE from $62 \%$ at the 12 -month time point, after a mean of $2.5 \mathrm{RFA}$ procedures. ${ }^{[42]}$ Endoscopic submucosal dissection (ESD) is now emerging as an alternative technique. Probst et al. showed that ESD is safe with higher complete removal of all tumor with microscopic examination of margins showing no tumor cells (R0 resection) in $83.9 \% .{ }^{[43]}$

\section{Reasons for Overuse of Endoscopy in Gastroesophageal Reflux Disease}

Common reasons for overuse of endoscopy are physician preference, ${ }^{[44]}$ patient satisfaction, ${ }^{[45]}$ and prevention of potential malpractice law suit. ${ }^{[46]}$ It has been noted that around $10-40 \%$ of EGD are not clinically indicated ${ }^{[47,48]}$ and the surveillance interval for $\mathrm{BE}$ is more intense in at least $30 \%$ of the patients in the community practice with open access endoscopy referral system. ${ }^{[49,47]}$ The range of EGD utilization for abdominal pain could be anywhere between $10 \%$ and $100 \%$ of patients enrolled. With increased awareness among patients, those with long standing reflux symptoms without any high risk features would also want to have a screening EGD to rule out any serious pathology. For patients with known $\mathrm{BE}$, the knowledge of harboring a precancerous lesion might cause anxiety and result in frequent surveillance EGDs.

\begin{tabular}{ll}
\hline \multicolumn{2}{l}{ Table 4: Vienna classification of esophageal neoplasia } \\
\hline Category & Description \\
\hline 1 & No dysplasia \\
2 & Indefinite for dysplasia \\
3 & Low-grade intraepithelial neoplasia (low-grade \\
& adenoma/dysplasia) \\
4 & $\begin{array}{l}\text { High-grade intraepithelial neoplasia } \\
\text { (high-grade adenoma/dysplasia, noninvasive } \\
\text { carcinoma, or suspicion of invasive carcinoma) } \\
\text { Invasive epithelial neoplasia (intramucosal }\end{array}$ \\
& carcinoma, submucosal carcinoma, or beyond)
\end{tabular}


The common reasons for the failure of GERD treatment are compliance with PPI and adherence to PPI. ${ }^{[5]}$ In a recent study, approximately $40 \%$ of primary care practitioners and around $20 \%$ of gastroenterologists were not aware of the proper timing and indication of PPI. ${ }^{[51]}$

\section{Summary and Recommendations on Use of Endoscopy in Gastroesophageal Reflux Disease Patients}

In summary, the role of endoscopy in GERD patients is limited. Patients with alarm symptoms such as weight loss, anemia, vomiting, and bleeding should undergo EGD to rule out the presence of strictures or cancer. Benign strictures can be dilated for symptom relief. It should be used to screen $\mathrm{BE}$ only in patients with high risk features. Patients with $\mathrm{BE}$ should be educated regarding their low risk of cancer and enrollment in endoscopic surveillance programs can be considered.

Patients with reflux symptoms and the absence of high risk features should be treated empirically with PPI for 4-8 weeks. For those patients, who are not responsive to PPI, adherence and compliance to PPI use should be monitored. Changing to a different PPI, doubling the dose, or addition of night-time histamine 2 receptor antagonists are all reasonable options. In the absence of response to conservative treatments, EGD is warranted. For patients with extraesophageal symptoms, a multi-specialty approach with participation of ENT, pulmonary, and cardiology services should be considered to rule other pathologies.

The use of EGDs becomes more critical for developing countries such as India where the prevalence of GERD and $\mathrm{BE}$ is comparable to the Western countries but have limited resources. The prevalence of GERD and BE may rise in future in India due to increase in prevalence of metabolic syndrome, aging population, and obesity. In addition to direct cost for an EGD, it burdens the economy with indirect costs such as time off from the work, transportation, and any procedural complications. Risk stratifying patients with GERD may, therefore, prevent unnecessary procedures, harms, and costs. This can be achieved through patient and primary care physician education as well as an emphasis on the current and effective standard of care by gastroenterologists.

\section{Financial support and sponsorship}

Nil.

\section{Conflicts of interest}

There are no conflicts of interest.

\section{References}

1. Vakil N, van Zanten SV, Kahrilas P, Dent J, Jones R; Global Consensus Group. The Montreal definition and classification of gastroesophageal reflux disease: A global evidence-based consensus. Am J Gastroenterol 2006;101:1900-20.

2. Dent J, El-Serag HB, Wallander MA, Johansson S. Epidemiology of gastro-oesophageal reflux disease: A systematic review. Gut 2005;54:710-7.

3. Locke GR $3^{\text {rd }}$, Talley NJ, Fett SL, Zinsmeister AR, Melton LJ $3^{\text {rd }}$. Prevalence and clinical spectrum of gastroesophageal reflux: A population-based study in Olmsted County, Minnesota. Gastroenterology 1997;112:1448-56.

4. Nebel OT, Fornes MF, Castell DO. Symptomatic gastroesophageal reflux: Incidence and precipitating factors. Am J Dig Dis 1976;21:953-6.

5. Charles RJ, Cooper GS, Wong RC, Sivak MV Jr, Chak A. Effectiveness of open-access endoscopy in routine primary-Care practice. Gastrointest Endosc 2003;57:183-6.

6. Sharma P, Wani S, Romero Y, Johnson D, Hamilton F. Racial and geographic issues in gastroesophageal reflux disease. Am J Gastroenterol 2008;103:2669-80.

7. Bhatia SJ, Reddy DN, Ghoshal UC, Jayanthi V, Abraham P, Choudhuri G, et al. Epidemiology and symptom profile of gastroesophageal reflux in the Indian population: Report of the Indian Society of Gastroenterology Task Force. Indian J Gastroenterol 2011;30:118-27.

8. Kumar S, Shivalli S. Prevalence, perceptions and profile of gastroesophageal reflux disease in a rural population of North Bihar. Natl J Community Med 2014;5:214-8.

9. Chang CY, Lee YC, Lee CT, Tu CH, Hwang JC, Chiang H, et al. The application of Prague $\mathrm{C}$ and $\mathrm{M}$ criteria in the diagnosis of Barrett's esophagus in an ethnic Chinese population. Am J Gastroenterol 2009;104:13-20.

10. Akiyama T, Inamori $\mathrm{M}$, Akimoto $\mathrm{K}$, Iida $\mathrm{H}$, Mawatari $\mathrm{H}$, Endo $\mathrm{H}$, et al. Risk factors for the progression of endoscopic Barrett's epithelium in Japan: A multivariate analysis based on the Prague C and M Criteria. Dig Dis Sci 2009;54:1702-7.

11. Punia RS, Arya S, Mohan H, Duseja A, Bal A. Spectrum of clinico-pathological changes in Barrett oesophagus. J Assoc Physicians India 2006;54:187-9.

12. Wani IR, Showkat HI, Bhargav DK, Samer M. Prevalence and risk factors for barrett's esophagus in patients with GERD in Northern India; do methylene blue-directed biopsies improve detection of Barrett's esophagus compared the conventional method? Middle East J Dig Dis 2014;6:228-36.

13. Peery AF, Dellon ES, Lund J, Crockett SD, McGowan CE, Bulsiewicz WJ, et al. Burden of gastrointestinal disease in the United States: 2012 update. Gastroenterology 2012;143:1179-87.e1-3.

14. Ronkainen J, Aro P, Storskrubb T, Johansson SE, Lind T, Bolling-Sternevald E, et al. High prevalence of gastroesophageal reflux symptoms and esophagitis with or without symptoms in the general adult Swedish population: A Kalixanda study report. Scand J Gastroenterol 2005;40:275-85.

15. Richter JE, Kahrilas PJ, Johanson J, Maton P, Breiter JR, Hwang C, et al. Efficacy and safety of esomeprazole compared with omeprazole in GERD patients with erosive esophagitis: A randomized controlled trial. Am J Gastroenterol 2001;96:656-65.

16. Moayyedi P, Talley NJ. Gastro-oesophageal reflux disease. Lancet 2006;367:2086-100.

17. Richter JE. Diagnostic tests for gastroesophageal reflux disease. Am J Med Sci 2003;326:300-8.

18. Galmiche JP, Barthelemy P, Hamelin B. Treating the symptoms of gastro-oesophageal reflux disease: A double-blind comparison of omeprazole and cisapride. Aliment Pharmacol Ther 1997;11:765-73.

19. Venables TL, Newland RD, Patel AC, Hole J, Wilcock C, Turbitt ML. Omeprazole 10 milligrams once daily, omeprazole 20 milligrams once daily, or ranitidine 150 milligrams twice daily, evaluated as initial therapy for the relief of symptoms of gastro-oesophageal reflux disease in general practice. Scand J Gastroenterol 1997;32:965-73.

20. Rath HC, Timmer A, Kunkel C, Endlicher E, Grossmann J, Hellerbrand C, et al. Comparison of interobserver agreement for different scoring systems for reflux esophagitis: Impact of level of experience. Gastrointest Endosc 2004;60:44-9. 
21. Ismail-Beigi F, Pope CE $2^{\text {nd }}$. Distribution of the histological changes of gastroesophageal reflux in the distal esophagus of man. Gastroenterology 1974;66:1109-13.

22. Ismail-Beigi F, Horton PF, Pope CE $2^{\text {nd }}$. Histological consequences of gastroesophageal reflux in man. Gastroenterology 1970;58:163-74.

23. Vieth M, Peitz U, Labenz J, Kulig M, Nauclér E, Jaspersen D, et al. What parameters are relevant for the histological diagnosis of gastroesophageal reflux disease without Barrett's mucosa? Dig Dis 2004;22:196-201.

24. Calabrese C, Fabbri A, Bortolotti M, Cenacchi G, Areni A, Scialpi C, et al. Dilated intercellular spaces as a marker of oesophageal damage: Comparative results in gastro-oesophageal reflux disease with or without bile reflux. Aliment Pharmacol Ther 2003;18:525-32.

25. Caviglia R, Ribolsi M, Maggiano N, Gabbrielli AM, Emerenziani S, Guarino MP, et al. Dilated intercellular spaces of esophageal epithelium in nonerosive reflux disease patients with physiological esophageal acid exposure. Am J Gastroenterol 2005;100:543-8.

26. Kamat P, Wen S, Morris J, Anandasabapathy S. Exploring the association between elevated body mass index and Barrett's esophagus: A systematic review and meta-analysis. Ann Thorac Surg 2009;87:655-62.

27. Lenglinger J, Riegler M, Cosentini E, Asari R, Mesteri I, Wrba F, et al. Review on the annual cancer risk of Barrett's esophagus in persons with symptoms of gastroesophageal reflux disease. Anticancer Res 2012;32:5465-73.

28. Inadomi JM, Sampliner R, Lagergren J, Lieberman D, Fendrick AM, Vakil N. Screening and surveillance for Barrett esophagus in high-risk groups: A cost-utility analysis. Ann Intern Med 2003;138:176-86.

29. American Gastroenterological Association, Spechler SJ, Sharma P, Souza RF, Inadomi JM, Shaheen NJ. American Gastroenterological Association medical position statement on the management of Barrett's esophagus. Gastroenterology 2011;140:1084-91.

30. ASGE Standards of Practice Committee, Evans JA, Early DS, Fukami N, Ben-Menachem T, Chandrasekhara V, et al. The role of endoscopy in Barrett's esophagus and other premalignant conditions of the esophagus. Gastrointest Endosc 2012;76:1087-94.

31. Wang KK, Sampliner RE; Practice Parameters Committee of the American College of Gastroenterology. Updated guidelines 2008 for the diagnosis, surveillance and therapy of Barrett's esophagus. Am J Gastroenterol 2008;103:788-97.

32. Shaheen NJ, Weinberg DS, Denberg TD, Chou R, Qaseem A, Shekelle P; Clinical Guidelines Committee of the American College of Physicians. Upper endoscopy for gastroesophageal reflux disease: Best practice advice from the clinical guidelines committee of the American College of Physicians. Ann Intern Med 2012;157:808-16.

33. Phoa KN, Pouw RE, van Vilsteren FG, Sondermeijer CM, Ten Kate FJ, Visser M, et al. Remission of Barrett's esophagus with early neoplasia 5 years after radiofrequency ablation with endoscopic resection: A Netherlands cohort study. Gastroenterology 2013;145:96-104.

34. van Vilsteren FG, Pouw RE, Seewald S, Alvarez Herrero L, Sondermeijer CM, Visser M, et al. Stepwise radical endoscopic resection versus radiofrequency ablation for Barrett's oesophagus with high-grade dysplasia or early cancer: A multicentre randomised trial. Gut 2011;60:765-73.

35. Gupta M, Iyer PG, Lutzke L, Gorospe EC, Abrams JA, Falk GW, et al. Recurrence of esophageal intestinal metaplasia after endoscopic mucosal resection and radiofrequency ablation of Barrett's esophagus: Results from a US Multicenter Consortium. Gastroenterology 2013;145;1:79-86.
36. Qumseya BJ, Wang H, Badie N, Uzomba RN, Parasa S, White DL, et al. Advanced imaging technologies increase detection of dysplasia and neoplasia in patients with Barrett's esophagus: A meta-analysis and systematic review. Clin Gastroenterol Hepatol 2013;11:1562-70.e1-2.

37. Sharma P, Hawes RH, Bansal A, Gupta N, Curvers W, Rastogi A, et al. Standard endoscopy with random biopsies versus narrow band imaging targeted biopsies in Barrett's oesophagus: A prospective, international, randomised controlled trial. Gut 2013;62:15-21.

38. Standards of Practice Committee, Egan JV, Baron TH, Adler DG, Davila R, Faigel DO, et al. Esophageal dilation. Gastrointest Endosc 2006;63:755-60.

39. Schlemper RJ, Riddell RH, Kato Y, Borchard F, Cooper HS, Dawsey SM, et al. The Vienna classification of gastrointestinal epithelial neoplasia. Gut 2000;47:251-5.

40. Dunbar KB, Spechler SJ. The risk of lymph-node metastases in patients with high-grade dysplasia or intramucosal carcinoma in Barrett's esophagus: A systematic review. Am J Gastroenterol 2012;107:850-62.

41. Buskens CJ, Westerterp M, Lagarde SM, Bergman JJ, ten Kate FJ, van Lanschot, et al. Prediction of appropriateness of local endoscopic treatment for high-grade dysplasia and early adenocarcinoma by EUS and histopathologic features. Gastrointest Endosc 2004;60:703-10.

42. Haidry RJ, Dunn JM, Butt MA, Burnell MG, Gupta A, Green S, et al. Radiofrequency ablation and endoscopic mucosal resection for dysplastic Barrett's esophagus and early esophageal adenocarcinoma: Outcomes of the UK National Halo RFA Registry. Gastroenterology 2013;145:87-95.

43. Probst A, Aust D, Märkl B, Anthuber M, Messmann H. Early esophageal cancer in Europe: Endoscopic treatment by endoscopic submucosal dissection. Endoscopy 2015;47:113-21.

44. Falk GW, Ours TM, Richter JE. Practice patterns for surveillance of Barrett's esophagus in the United States. Gastrointest Endosc 2000;52:197-203.

45. Shaheen NJ, Green B, Medapalli RK, Mitchell KL, Wei JT, Schmitz SM, et al. The perception of cancer risk in patients with prevalent Barrett's esophagus enrolled in an endoscopic surveillance program. Gastroenterology 2005;129:429-36.

46. Rubenstein JH, Saini SD, Kuhn L, McMahon L, Sharma P, Pardi DS, et al. Influence of malpractice history on the practice of screening and surveillance for Barrett's esophagus. Am J Gastroenterol 2008;103:842-9.

47. Hassan C, Bersani G, Buri L, Zullo A, Anti M, Bianco MA, et al. Appropriateness of upper-GI endoscopy: An Italian Survey on Behalf of the Italian Society of Digestive Endoscopy. Gastrointest Endosc 2007;65:767-74.

48. Rossi A, Bersani G, Ricci G, Defabritiis G, Pollino V, Suzzi A, et al. ASGE guidelines for the appropriate use of upper endoscopy: Association with endoscopic findings. Gastrointest Endosc 2002;56:714-9.

49. Gonvers JJ, Burnand B, Froehlich F, Pache I, Thorens J, Fried M, et al. Appropriateness and diagnostic yield of upper gastrointestinal endoscopy in an open-access endoscopy unit. Endoscopy 1996;28:661-6.

50. Gunaratnam NT, Jessup TP, Inadomi J, Lascewski DP. Sub-optimal proton pump inhibitor dosing is prevalent in patients with poorly controlled gastro-oesophageal reflux disease. Aliment Pharmacol Ther 2006;23:1473-7.

51. Barrison AF, Jarboe LA, Weinberg BM, Nimmagadda K, Sullivan LM, Wolfe MM. Patterns of proton pump inhibitor use in clinical practice. Am J Med 2001;111:469-73. 